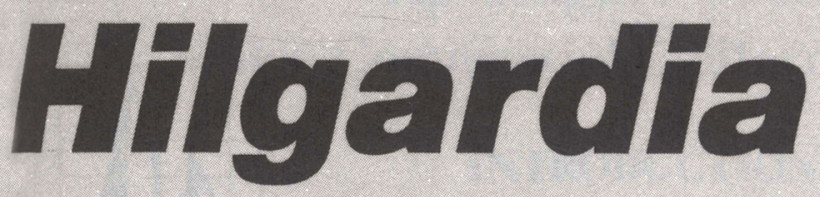

A JOURNAL OF AGRICULTURAL SCIENCE PUBLISHED BY THE CALIFORNIA AGRICULTURAL EXPERIMENT STATION

Volume 62 - Number 4 December 1995

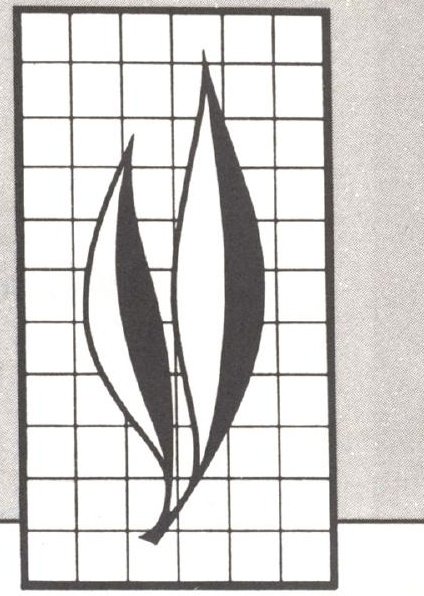

\title{
Tip Length Models for Major Commercial California Conifers
}

Craig M. Olson and Lee C. Wensel 


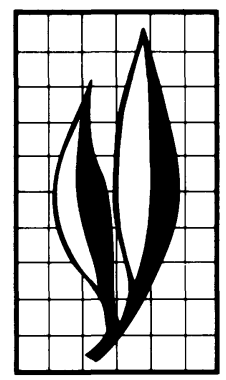

\begin{abstract}
Several models for predicting the length from the merchantable top to the tip of a tree are evaluated for major California conifers. A model reported by Wensel and Krumland (1983) was found to be the most useful because of its ability to predict for both total height or merchantable height. Coefficients are reported for eight commercially important conifers of California.
\end{abstract}

\title{
THE AUTHORS:
}

Craig M. Olson is Research Associate, Department of Environmental Science Policy and Management, University of California, Berkeley, CA 94720.

Lee C. Wensel is Professor, Department of Environmental Science Policy and Management, University of California, Berkeley, CA 94720. 


\section{Tip Length Models for Major Commercial California Conifers ${ }^{1}$}

\section{INTRODUCTION}

Field Measurements may provide only total height on the trees when height to a fixed merchantable diameter is needed for merchantable volume estimation. Alternatively, most stem taper equations are based upon knowing the total height of the tree (e.g., Max and Burkhart 1976; Biging 1984; Kozak 1988; McTague and Stansfield 1988; Wensel and Olson 1995), tree height is often measured in number of logs to a fixed (merchantable) inside-bark diameter. Therefore, the objective here is to provide equations and coefficients to enable one to predict the tip length to make easy conversions between total tree height and merchantable heights.

Wensel and Krumland (1983) developed a tip model for redwood and Douglasfir for this very purpose. In this study we investigated using Wensel and Krumland's model, as well as several other models, so that whole tree taper models could be used to estimate diameters up the stem of a tree when only the height to some upper diameter is known. An alternative approach for finding the length of stem from a merchantable top to tip is to iteratively solve the taper function, finding that total height consistent with the merchantable top diameter, the merchantable height, and the diameter at breast height.

The objective here was to find the appropriate tip model and then calculate the coefficient values for the eight species listed below.

Species considered are Douglas-fir, Pseudotsuga menziesii (Mirb.) Franco; ponderosa pine, Pinus ponderosa Dougl. ex Laws.; Jeffrey pine, P. jeffreyi Grev. \& Balf.; lodgepole pine, $P$. contorta Dougl. ex Loud.; sugar pine, $P$. lambertiana Dougl.; white fir, Abies concolor (Gord. \& Glend.) Lindl. ex Hildebr.; red fir, A. magnifica A. Murr.; and incense-cedar, Calocedrus decurrens (Torr.) Florin.

\section{TIP LENGTH MODELS CONSIDERED}

Several tip models were investigated for their use as predictors of stem length from a merchantable top to tip. The first was developed by Wensel and Krumland (1983):

$$
\text { Tip }=b_{0} \text { DTOP }^{b_{1}} \text { DBH }^{b_{2}}
$$

where Tip = length in feet from merchantable top to tip, DTOP = merchantable top diameter in inches, and DBH = diameter in inches at breast height. Two alternative models included:

$$
\mathrm{Tip}=\mathrm{b}_{0} \mathrm{DTOP}^{\mathrm{b}_{1} \mathrm{MHT}^{\mathrm{b}_{2}}}
$$

where $\mathrm{MHT}=$ height to the merchantable top diameter, and,

'Accepted for publication May 30, 1995. 


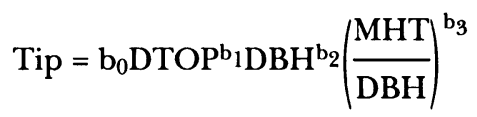

The MHT to DBH ratio was used expecting that short, fat trees would have a shorter top for a given diameter than tall, skinny trees of the same diameter. The models were fit in their nonlinear form using a least squares algorithm.

An alternative to using direct predictions of tip length is to use a stem taper equation, where total height (THT) in feet is predicted from merchantable height by an iterative process. If the taper equation is accurate at the top, this process would give adequate estimates of tip length. Using the stem taper function from Wensel and Olson (1995) we solved for total height, knowing the DBH, top diameter (dib) in inches, height to that diameter (HT) in feet, and species. Wensel and Krumland's model was used as the stem taper model using coefficients fitted by Wensel and Olson (1995):

$$
\operatorname{dib}=\mathrm{DBH}\left(\mathrm{c}_{0}-\mathrm{f} \ln \left(1-\mathrm{R}^{\mathrm{c}_{1}}\left[1-\exp \left(\frac{\mathrm{c}_{0}}{\mathrm{f}}\right)\right]\right)\right)
$$

where $c_{i}=$ the ith coefficient $(i=0 \ldots 4), R=\frac{H T-1}{\text { THT }-1}, f=c_{2}+c_{3}$ DBH $+c_{4}$ THT and ln refers to the natural logarithm (base e). An initial THT was estimated and evaluated for consistency with the dib, HT, and DBH. If the estimated THT was too great for the corresponding dib, HT, and DBH the estimated THT minus HT length was halved and the new estimated THT evaluated. This process was continued until the estimated THT was consistent with the dib, HT, and DBH to within 0.1 feet.

\section{DATA SOURCES}

The data used in this study came from stem analysis of felled trees and optical dendrometer measurements on standing trees (Wensel and Olson 1995). Observations in this data set with top diameters from 4 to 9 inches and known total height were used to estimate and compare the various models (see Table 1). Table 1 shows the number of observations and the mean, minimum, and maximum for the top diameters, DBH, and total height for the eight conifer species considered here. Since tip length has little meaning in old-growth trees, which frequently go from 20 inches, say, to zero in only a short distance and often have multiple tops, these data are not included in the analysis. Further, these models are not intended for use with old-growth trees or trees with multiple or broken tops. 
TABLE 1. NUMBER OF TREES, MEAN, MINIMUM, AND MAXIMUM TOP DIAMETER, DIAMETER AT BREAST HEIGHT, AND TOTAL HEIGHT USED TO EVALUATE STEM TIP MODELS

\begin{tabular}{|c|c|c|c|c|c|c|c|c|c|c|}
\hline \multirow[b]{2}{*}{ Species } & \multirow[b]{2}{*}{ Trees } & \multicolumn{3}{|c|}{ Top diameter } & \multicolumn{3}{|c|}{ DBH } & \multicolumn{3}{|c|}{ Height } \\
\hline & & Mean & Min & $\operatorname{Max}$ & Mean & Min & $\operatorname{Max}$ & Mean & Min & $\operatorname{Max}$ \\
\hline & no. & & inches & & & inches & & & feet & \\
\hline Douglas-fir & 1098 & 6.7 & 4.0 & 9.0 & 26.6 & 11.0 & 73.7 & 121.3 & 51.7 & 265.0 \\
\hline Ponderosa pine & 1915 & 6.4 & 4.0 & 9.0 & 22.0 & 11.0 & 58.4 & 100.4 & 34.2 & 200.0 \\
\hline Jeffrey pine & 106 & 5.3 & 4.0 & 8.0 & 17.1 & 11.0 & 25.3 & 66.0 & 38.0 & 96.0 \\
\hline Sugar pine & 713 & 6.9 & 4.0 & 9.0 & 26.5 & 11.3 & 60.0 & 107.4 & 41.0 & 202.0 \\
\hline Lodgepole pine & 66 & 6.9 & 4.5 & 8.8 & 16.5 & 12.1 & 26.1 & 64.6 & 37.5 & 95.3 \\
\hline White fir & 2655 & 6.4 & 4.0 & 9.0 & 20.8 & 11.0 & 45.0 & 92.8 & 39.1 & 206.2 \\
\hline Red fir & 1120 & 6.5 & 4.0 & 9.0 & 20.4 & 11.0 & 48.0 & 83.9 & 38.0 & 164.9 \\
\hline Incense-cedar & 622 & 6.1 & 4.0 & 9.0 & 26.1 & 11.0 & 64.0 & 82.2 & 24.4 & 155.0 \\
\hline
\end{tabular}

\section{RESULTS AND DISCUSSION}

All four of the above equations were used to estimate stem tip lengths. The least-squares fit of equations (1), (2) and (3) produced a minimally biased model with respect to the predictor variables. The mean absolute deviation for all species was under five feet and the overall mean bias was under 0.02 feet for all species and models. Equation (1) also has the desirable property that tip length can be predicted without knowing the tree height. The coefficient values and the mean squared error from fitting these models to the eight species appears in Tables 2a, $2 \mathrm{~b}$, and $2 \mathrm{c}$.

The mean squared errors for the eight species ranged from 6.7 to $38.0 \mathrm{ft}^{2}, 7.9$ to $42.9 \mathrm{ft}^{2}$, and 4.6 to $28.5 \mathrm{ft}^{2}$, for models (1), (2), and (3), respectively. However, in the case of Jeffrey pine and lodgepole pine there were very few observations and the magnitude of the MSE is larger, showing that it is more likely to be a function of the sample size than the quality of the model fit.

As one might expect, the greater the top diameter the greater the tip length, and conversely the greater the diameter at breast height the shorter the tip length. Equations (2) and (3) did not appreciably reduce the sums of squares or

TABLE 2a. FITTED COEFFICIENT VALUES FOR TIP MODEL (1) AND MEAN SQUARED ERROR (MSE) BY SPECIES

\begin{tabular}{lrccr}
\hline \hline Species & \multicolumn{1}{c}{$\mathbf{b}_{\mathbf{0}}$} & $\mathbf{b}_{\mathbf{1}}$ & $\mathbf{b}_{\mathbf{2}}$ & $\begin{array}{r}\text { MSE } \\
\text { feet }^{2}\end{array}$ \\
\hline Douglas-fir & 12.3427 & 0.94927 & -0.35726 & 33.6 \\
Ponderosa pine & 14.7499 & 1.08778 & -0.53401 & 31.1 \\
Jeffrey pine & 6.4090 & 1.22192 & -0.40190 & 6.7 \\
Sugar pine & 10.0843 & 1.16455 & -0.43810 & 38.0 \\
Lodgepole pine & 9.8857 & 0.94937 & -0.36134 & 18.6 \\
White fir & 9.0558 & 1.00807 & -0.34298 & 25.1 \\
Red fir & 11.6757 & 1.13426 & -0.55298 & 16.6 \\
Incense-cedar & 9.2386 & 1.04472 & -0.39884 & 27.7 \\
\hline
\end{tabular}


TABLE 2b. FITTED COEFFICIENT VALUES FOR TIP MODEL (2) AND MEAN SQUARED ERROR (MSE) BY SPECIES

\begin{tabular}{lrccr}
\hline Species & \multicolumn{1}{c}{$\mathbf{b}_{\mathbf{0}}$} & $\mathbf{b}_{1}$ & $\mathbf{b}_{\mathbf{2}}$ & $\begin{array}{r}\text { MSE } \\
\text { feet }^{2}\end{array}$ \\
\hline Douglas-fir & 14.8243 & 0.83418 & -0.24537 & 37.7 \\
Ponderosa pine & 9.8907 & 0.86594 & -0.18838 & 39.0 \\
Jeffrey pine & 4.1243 & 1.10247 & -0.12720 & 7.9 \\
Sugar pine & 11.1419 & 1.02969 & -0.28538 & 42.9 \\
Lodgepole pine & 9.3053 & 0.72138 & -0.13705 & 19.1 \\
White fir & 7.2390 & 0.86098 & -0.12553 & 27.5 \\
Red fir & 8.3651 & 0.88890 & -0.20631 & 21.3 \\
Incense-cedar & 7.3864 & 0.89576 & -0.18823 & 32.5 \\
\hline
\end{tabular}

TABLE 2c. FITTED COEFFICIENT VALUES FOR TIP MODEL (3) AND MEAN SQUARED ERROR (MSE) BY SPECIES

\begin{tabular}{lccccr}
\hline \hline Species & $\mathbf{b}_{\mathbf{0}}$ & $\mathbf{b}_{\mathbf{1}}$ & $\mathbf{b}_{\mathbf{2}}$ & $\mathbf{b}_{\mathbf{3}}$ & $\begin{array}{r}\text { MSE } \\
\text { feet }^{2}\end{array}$ \\
\hline Douglas-fir & 2.5614 & 0.94398 & -0.14209 & -0.57217 & 28.5 \\
Ponderosa pine & 1.4300 & 1.08793 & -0.17646 & -0.80562 & 21.3 \\
Jeffrey pine & 1.6451 & 1.21353 & -0.23704 & -0.67098 & 4.6 \\
Sugar pine & 0.9411 & 1.02399 & -0.06041 & -0.99471 & 27.1 \\
Lodgepole pine & 2.7171 & 0.85061 & -0.05858 & -0.46491 & 16.3 \\
White fir & 1.7117 & 1.00203 & -0.11140 & -0.64960 & 19.8 \\
Red fir & 2.5830 & 1.13955 & -0.33157 & -0.58589 & 12.7 \\
Incense-cedar & 1.2125 & 1.00026 & -0.77524 & -0.91325 & 17.6 \\
\hline
\end{tabular}

reduce bias with respect to any of the predictor variables when compared to results from fitting equation (1). Since there was little or no improvement in model fit for equations (2) and (3), there was little advantage in knowing tree height for estimating tip length.

There is a systematic bias associated with tip estimates using the tree taper functions of Wensel and Olson (1995). Short tips ( $<25$ feet) are systematically overpredicted while long tips (> 25 feet) are consistently underpredicted. One can avoid such bias by using the tip models (1), (2), and (3), especially for the shorter trees (Figure 1). This bias existed for all eight species, particularly for trees of total height less than one hundred feet.

Results of using equation (4) can be seen in Figure 2. There is a systematic bias associated with iteratively solving the taper function to find the tip length. This bias is found for all eight species, particularly for trees of total height less than one hundred feet. Thus, not only is the iterative solution of the taper equation tedious, it is also biased. While we expect a similar result with other taper models, it is important to note that we only tested this with one taper model.

Finally, models (1), (2) and (3) were all found to work well for predicting tip lengths, but because of the ability of model (1) to predict merchantable height it is of more general use. The models fitted here are considered appropriate, for the species considered, for top diameters ranging from 4 to 9 inches in California. 

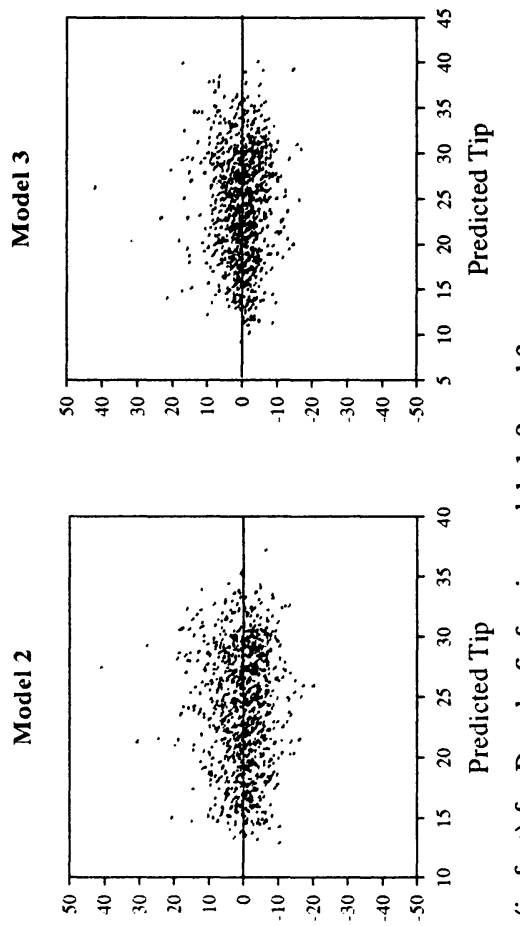

कृ

른
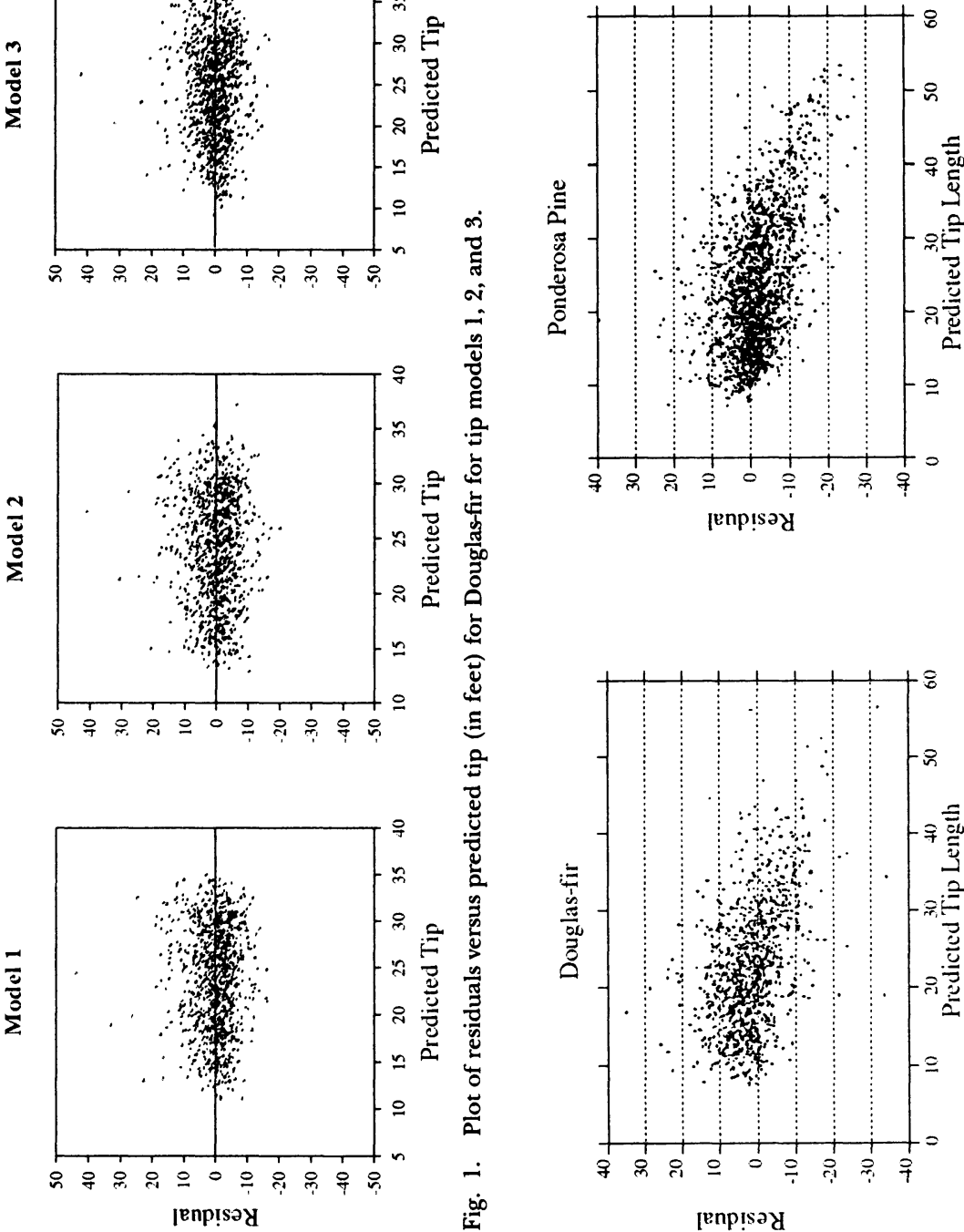

ن 


\section{LITERATURE CITED}

BIGING, G. S.

1984. Taper equations for second-growth mixed conifers of northern California. For. Sci. 30 (4): 1103-17.

KOZAK, A.

1988. A variable-exponent taper equation. Can. J. For. Res. 18: 1363-68.

MAX, T. A., and H. E. BURKHART

1976. Segmented polynomial regression applied to taper equations. For. Sci. 22(3): 283-89.

MCTAGUE, J. P., and W. F. STANSFIELD

1988. Total and merchantable volume equations and taper functions for southwestern ponderosa pine. West. J. Appl. For. 3(4):123-25.

WENSEL, L. C. and C. M. OLSON

1995. Tree taper models for major commercial California conifers. Hilgardia 62(3), 16 pp. (Published concurrently and bound in this volume.)

WENSEL, L. C. and B. KRUMLAND

1983. Volume and taper relationships for redwood, Douglas-fir, and other conifers in California's north coast. University of California, Division of Agricultural Sciences Bulletin 1907.

\section{ACKNOWLEDGMENTS}

The authors gratefully acknowledge the assistance of Kevin Casey, LeRoy Dolph, Ralph Johnson, Charles Stadelman, and Ralph Warbington of the U.S. Forest Service in helping to accumulate the data sets used for this study. 